\section{Redescubrir el valor del \\ periodismo en la \\ Venezuela del \\ presente}

Marcelino Bisbal
Por espacio público entendemos un ámbito de nuestra vida social, en el que se puede construir algo así como opinión pública. La entrada está fundamentalmente abierta a todos los ciudadanos. En cada conversación en la que los individuos privados se reúnen como público se constituye una porción de espacio público (...). Los ciudadanos se comportan como público, cuando se reúnen y conciertan libremente, sin presiones y con la garantía de poder manifestar y publicar libremente su opinión, sobre las oportunidades de actuar según intereses generales.

En los casos de un público amplio, esta comunicación requiere medios precisos de transferencia e influencia: periódicos $y$ revistas, radio y televisión son boy tales medios del espacio público.

J. HABERMAS

El poder sólo es realidad donde palabra y acto no se han separado, donde las palabras no están vacias y los hechos no son brutales, donde las palabras no se emplean para velar intenciones, sino para descubrir realidades, y los actos no se usan para violar y destruir, sino para establecer relaciones y crear nuevas realidades.

HANNAH ARENDT

\section{Los avatares del tiempo} ecir, a estas alturas del tiempo,
que "Venezuela cambió" es no apuntar ninguna novedad. Decir, en momentos de rabia y desesperación -cada vez más frecuentes- que volveremos a las escenas de antes de 1998 
es no haber entendido cómo el tiempo cotidiano fue anulando, por el ejercicio mismo de la práctica política y de la práctica ciudadana, la idea de proyecto social y de Estado-nación moderno y modernizante que había sido ideado por intelectuales y políticos de las más variadas ideas y pensamientos.

Estamos en presencia de un nuevo paisaje, en donde los rasgos más característicos son los siguientes:

- El Estado ha perdido los límites que lo definían y se ha transformado en un aparato amorfo, que cada vez más se va pareciendo a una "maquinaria" de control y secuestro de las instituciones.

- El protagonismo militar ha ido ocupando espacios civiles ante la mirada, si no complaciente de gran parte de la sociedad, por lo menos va resultando ya un hecho casi natural y lógico.

- Las necesidades económicas reflejadas en la inflación, el desempleo, el deterioro del sistema productivo privado, el excesivo gasto público que no es capaz de saciarse, la dependencia casi absoluta de la renta petrolera hasta límites que no eran pensables..., en fin, todas esas necesidades que han ido quebrando fuertemente el horizonte de expectativas que nos habíamos imaginado y soñado.

- La idea de crear un partido hegemónico y un proyecto hegemónico de nula cultura democrática, como es todo lo "único", como le gustaría referir a Michel Maffesoli.

- El excesivo personalismo que encarna la figura del Presidente de la República y que sacralizan sus partidarios y los más allegados al poder.

- La centralización como creencia de que desde allí "todo se va a resolver", sin comprender que uno de los logros y conquistas ciudadanas más significativos de nuestra historia democrática fue la descentralización administrativa en muchas esferas del poder del Estado.

- La evidente polarización y conflictualidad en la que vivimos y que lejos de desaparecer y disolverse ha ido acrecentándose por un discurso y una retórica de la exclusión, la confrontación y la violencia.

- El surgimiento, publicitado además, del resentimiento social como manera de querer comprender nuestras debilidades.

- El empeño de voltear la historia republicana intentando, de manera insensata y poco responsable, reescribirla desde el personalismo, el caudillismo y el mesianismo.

- La insistencia de construir un ¿proyecto de país? teniendo como modelos experiencias más que fracasadas y superadas por la historia de los acontecimientos recientes.

En síntesis, aunque referida a otra situación como fue la Argentina desde el instante en que el sistema político 
de ese país entró en un salto al vacío, de la represión militar y de la transición democrática, es la conclusión que explicita la catedrática de literatura de la Universidad de Buenos Aires Beatriz Sarlo, al escribir que:

Se ha producido un cisma cultural que reduplica el cisma económico; en el horizonte de las víctimas, se esfumaron las razones de pertenencia a una sociedad nacional; en todas partes se ha debilitado la idea de responsabilidad que, aun precariamente, teje la trama de muchos hilos que sostienen una comunidad. No se trata de salvar a los políticos de la responsabilidad sobre este paisaje, porque ellos se encargaron de que se profundizaran sus rasgos. Pero quienes forman parte de la cúpula de la pirámide social, los muy ricos pero también nosotros, por razones diferentes, hemos observado la catástrofe, unos en la persecución de beneficios inmediatos, otros sorprendidos por lo impensado (incluso quienes lo anunciaron quizás estén sorprendidos por el fulminante cumplimiento de sus predicciones). ${ }^{1}$

Y creo que en nuestro caso y experiencia es posible agregar, a la interpretación de Beatriz Sarlo, otra dimensión, aunque en el fondo responda a la misma idea conclusiva, como es la pérdida paulatina de la democracia $\mathrm{O}$ los peligros que la acechan. El politólogo y sociólogo chileno Fernando Mires publicaba recientemente, en el portal electrónico de la revista Nueva Sociedad, ${ }^{2}$ un texto que describe "los diez peligros de la democracia en América Latina" y que bien vale la pena que repasemos en forma esquemática cuáles son esos peligros, porque son los mismos que se hacen presentes en nuestra situación actual. En términos específicos los peligros serían o ¿serán?:

1. El peligro de la (re)militarización del poder. Dos citas bien explícitas del autor nos aclaran este primer peligro. Por un lado nos dice que:

Ha habido y probablemente seguirán habiendo generales latifundistas, modernizadores, nacionalistas, socializantes, desarrollistas, neoliberales, populistas, etc. Lo único que no vamos a encontrar, porque es un contrasentido, son generales democráticos, por lo menos no cuando ocupen el Estado. Los militares en el poder, independientemente de ideologías, proyectos, modelos y locuras, han sido el resultado de la precariedad del desarrollo político latinoamericano, precariedad que esos mismos militares han acentuado notablemente.

1 SARLO, Beatriz. "Ser argentino: ya nada será igual". VARIOS AUTORES. Imaginarios de nación. Bogotá: Ministerio de Cultura de Colombia, 2001, p. 51.

2 MIRES, Fernando. "Los diez peligros de la democracia en América Latina" [en línea]. <http//www.nueva soc.org.ve>. Sección de Intervenciones.

Contratexto n. 14, 2006 
Y por el otro:

Cuando la ausencia de politicidad es manifiesta o cuando las estructuras políticas han sido destruidas (a veces por los propios políticos) suele ocurrir, y ha ocurrido, y no sólo en América Latina, que poderes no políticos ocupen el lugar reservado al poder político. Ya establecidos en ese lugar, realizan, aunque sea una paradoja, una política de la antipolítica que es la que sin excepción caracteriza a todas las dictaduras en cualquier lugar del mundo.

\section{El peligro de la economización de la} política. En el sentido de que:

El discurso económico dominante ha sido asumido por los propios políticos, quienes se ven en la obligación de presentarse como expertos en materias económicas, aunque muchas veces solo dominan las operaciones aritméticas básicas. Más aún: cuando se encuentran en períodos electorales, la mayoría de sus promesas son económicas. De este modo intentan comprar indirectamente los votos de la población. Casi todos ofrecen crecimiento, bienestar, fuentes de trabajo, aumentos de salarios, pero sin tener idea acerca de cómo van a realizar lo que prometen. Temas políticos propiamente, como las libertades públicas, el aumento de los espacios de discusión, la aplicación consecuente de los derechos humanos, etc., son casi siempre dejados de la mano. De este modo, para los electores comunes y corrientes, la boleta electoral tiene un significado similar a una tarjeta de crédito. Votando por tal o cual imaginan adquirir un futuro econó- micamente promisorio que por supuesto nunca llega, pues los ritmos del desarrollo económico son muy diferentes a los de la política.

3. El peligro de la corrupción. La interpretación de Mires es que la corrupción es casi imposible de erradicar, pero ella sí puede ser limitada si se actúa con transparencia y sentido democrático. Y nos dice que:

Un gobierno puede ser limpio y puro, pero si las instituciones intermedias han sido corrompidas, apenas podrá gobernar. Y cuando la corrupción no solo es política sino también social, es decir, generalizada, la democracia política no puede prosperar en ninguna parte. Cuando la nación comienza a corromperse, no sólo vertical sino también horizontalmente, ha llegado la hora de los golpistas, o de los demagogos, o de los populistas, o de todo eso a la vez. El tan conocido fenómeno del populismo latinoamericano es en gran medida un resultado de la corrupción de las instituciones públicas, y por cierto, uno de los peligros más grandes para cualquier proceso democrático.

4. El peligro populista. Como nos explica el autor, el peligro del populismo se aprecia en la pretensión de sus representantes de cerrar las líneas divisorias que hacen de la política, y por lo mismo de la democracia, un campo de representación de diversas posiciones. Puntualiza que: 
En el simbolismo radical del populismo las líneas divisorias que separan al pueblo entre sí son transportadas en contra de enemigos que pueden ser reales, pero también imaginados. Ese agente externo de negación constitutiva de la afirmación popular puede ser muy diverso: puede ser la nación enemiga, pueden ser los extranjeros que habitan el país, pueden ser los ricos, los corruptos, la oligarquía, el imperialismo, la globalización, es decir, puede ser cualquier cosa que opere como representación simbólica del mal absoluto contra el bien total representado por la voluntad popular -y esta es una de las características esenciales del populismo- corporizada por un líder carismático cuya función es trasladar las diferencias hacia el exterior del pueblo, para que el pueblo siga imaginando que es un solo pueblo. Todo populismo se expresa necesariamente en la personificación extrema del poder.

\section{El peligro de la personificación ex-} trema del poder. Este peligro, como apunta Mires, es consecuencia directa del anterior. Es decir, cuando la política tiende a ser populista, esta debe representarse en diferentes personas que simbolizan la unidad de diferentes actores.

Lamentablemente, cuando el personalismo político alcanza un grado extremo, el representante político se convierte en el principal objeto de discusión. En esas circunstancias es muy fácil que si él no es contenido a tiempo, caiga en excesos representativos o en fantasías omnipotentes. Ello se puede observar en el curso de su retórica. Casi siempre tiende a abusar del tiempo del ciudadano y a hablar mucho más allá de lo que es políticamente necesario. Sus discursos serán cada vez más emocionales; y suele suceder que abandone el lenguaje de la discusión y caiga fácilmente en la invectiva y en la descalificación. La violencia de las palabras no tarda en esos casos en traducirse en violencia de los hechos. Poco a poco la lógica argumentativa será reemplazada por gritos y signos mágicos, y las multitudes en las calles se dejarán llevar más por la uniformidad de los colores de banderas, camisas o boinas, o por la rima de consignas gritadas a coro, que por sus intereses e ideales. En síntesis, la política, y sin que sus actores se den cuenta, entra en un abierto proceso de facistización. Las estructuras populares se convierten en un pueblo; el pueblo se disuelve en masa y la masa en chusma.

6. El peligro de la desigualdad social. Interpretando al autor, él nos dirá que el hecho de que exista desigualdad y pobreza extrema no son condiciones que imposibiliten la democracia sino al contrario. Será un reto para la democracia lograr superar esas condiciones, aun a sabiendas de que esas situaciones no son el mejor terreno para construir democracias. Lo que sucede es que los populistas se valen del hecho de la desigualdad social para levantar promesas de su erradicación sin lograrlo en el tiempo por falta de políticas coherentes y eficaces: 
En este sentido, las dificultades para erigir un orden democrático, más que de las desigualdades sociales provienen de un mal entendido que conviene dejar en claro. Ese no es otro que aquel que afirma que la tarea inmediata de toda democracia debe ser la de superar las condiciones que determina la pobreza social. Ese malentendido es generalmente propagado por los propios políticos, pues como ya se dijo anteriormente, la mayoría de ellos tiene la opinión de que son excelentes expertos en materia de economía; es decir, se trata de una creencia derivada del peligro de la 'economización de la política'.

\section{El peligro de la desintegración poli-} tica. Este peligro tiene varias facetas. Desde nuestro contexto es preciso señalar aquella que hace referencia a la llamada gobernabilidad.

Cuando la gobernabilidad es precaria, ella se traduce en un desgobierno de las conductas sociales e incluso de la ética individual. La desintegración parece por lo tanto ser consustancial a esa transición, y en algunos casos es tan avanza$\mathrm{da}$, que las expresiones delictivas escapan a cualquier posibilidad de control social y deben ser enfrentadas policialmente (...) ahí donde no hay política, hay policía. Pero si la policia es parte de esa desintegración total, y en algunos países lo es, las alternativas de democratización de la vida social son muy pocas.

\section{El peligro de la etnización de la po-} lítica. Aun cuando en Venezuela ese no sea un peligro inminente, sin embargo hemos tenido algunos brotes de tal postura. Allí está el planteamiento que se hizo desde el mismo gobierno, a propósito de los festejos del "Día de la Raza", rebautizando el 12 de octubre como el "Día de la Resistencia Indígena" y que ya ha comenzado a formar parte de los manuales escolares. Como nos dice el autor:

El peligro de la etnización de la política es muy actual y tiene que ver en parte con influjos ideológicos que provienen desde fuera de las comunidades indígenas, particularmente desde fracciones de una izquierda antipolítica que después del derrumbe del comunismo busca nuevos actores que le permitan mantener una actitud confrontativa respecto a todo gobierno y con ello conservar su propia identidad. El indigenismo es, para esas izquierdas, una entre otras teorías de sustitución. De ahí que siempre es necesario diferenciar entre las demandas de las comunidades indígenas y agrarias, y las ideologías que les han sido superpuestas.

9. El peligro de la ausencia (o de la escasa presencia) de una intelectualidad politica. Es la confrontación entre el pensamiento ideológico y el pensamiento crítico. Para el primero las conclusiones, antes de que los hechos se sucedan, ya están dadas; pero para el segundo el análisis y la reflexión de los conflictos reales son condiciones necesarias de comprensión. 
En el espacio que ocupa la llamada intelectualidad hay en cada nación una franja delgada desde donde son producidas ideas que serán reformuladas en diferentes espacios de acción. Puede que los actores de esa franja no se definan a sí mismos como políticos, pero su incidencia política es importante, pues, en la medida en que ellos piensan, la nación (otros dicen 'la sociedad') se piensa a sí misma. De ahí que cuando se habla de la crisis de la política no sólo es la política la que está en crisis sino que también lo están aquellos que tienen que producir ideas para que la política sea posible. Muchas veces una crisis política no es sino una crisis intelectual reflejada en la política.

\section{El peligro del democratismo. Nada} en exceso, se suele decir popularmente, es bueno y productivo. Como nos plantea entonces Fernando Mires, un exceso de democracia puede ser nocivo para la propia democracia. La idea es textualmente la siguiente:

La voluntad mayoritaria puede llegar a ser una voluntad dictatorial si es que la acción de las minorías no se encuentra plenamente garantizada en el juego político. En ese sentido, hay democracias que no son demasiado políticas, pues en nombre de las mayorías son reducidos los campos de acción de las minorías. Si bien la democracia implica el gobierno de la mayoría, la política implica las luchas de las minorías para llegar a ser mayorías. Si a las minorías se les niega esa posibilidad, es suspendido el juego político al interior de una democracia y con ello la democracia misma comienza a ex- tinguirse. Ningún gobierno puede usar el recurso de la mayoría para reprimir a minorías y seguir llamándose a sí mismo democrático. La mayoría otorga el gobierno; pero no un cheque en blanco al gobernante. El democratismo no siempre es democrático.

$\mathrm{Y}$ es que este país, y nosotros sus ciudadanos, está viviendo una situación límite que no hemos sido capaces de conjurar ni a través de las especulaciones intelectuales, y mucho menos por las mediaciones de la oposición gubernamental, ni del gobierno mismo, pero tampoco por el cruzamiento de discursos e imágenes diversos que día a día nos van presentando, incluso imponiendo, los medios de comunicación social, tanto los de un frente como los del otro. En fin...

¿Cómo responsabilizarnos entonces de nuestros errores y nuestros fracasos si no compartimos el discurso en que podríamos nombrarlos?, ¿cómo compartir duelos si ni siquiera podemos llorar juntos?, ¿qué es aquel mínimo sin el cual no hay comunidad que subsista? Ahí radica la gravedad última de una situación en la que hasta la lectura que de ella hace la clase pensante, los intelectuales y las ciencias sociales, en lugar de contribuir a tejer convergencias, tiende aun a fragmentar y polarizar la sociedad, ya que no hemos logrado poner en común una lectura en la que sea posible dirimir hasta dónde llega lo tolerable y comienza lo intolerable. Los intelectuales no estamos proporcionando a este país una lectura de la situación -no confundir con coyun- 
tura- que ayude a la gente a ubicar su cotidiana experiencia de dolor tanto como las retazos de sentido que alientan nuestra esperanza. ${ }^{3}$

\section{El contexto emergente}

Los ecos de esos planteamientos de Beatriz Sarlo, a partir de la experiencia vivida y sufrida -como dice la autora-, y los del chileno Fernando Mires, estudiando los signos que se muestran Como verdaderos peligros en esta América Latina de aquí y ahora, se hacen visibles en la Venezuela del presente. Diríamos que demasiado visibles y hasta coincidentes para el momento actual y que hace que hoy empecemos a dudar de la supervivencia de la libertad y la democracia como hechos reales y tangibles. Entendidas la libertad y la democracia en su sentido habermasiano, es decir, la presencia de un espacio libre y democrático, no coercitivo por ninguna forma de poder, para "el libre juego de la opinión pública como motor de la política democrática en su sentido real y empírico y en un sentido normativo". 4 Como vemos, para J. Habermas el espacio público libre y democrático será el lugar donde se hagan visibles las más diversas contradic- ciones de la vida social y política, y Habermas entenderá la "esfera pública burguesa" como la aparición de un espacio en donde "... el interés público de la esfera privada en la sociedad burguesa deja de ser percibido exclusivamente para la autoridad y comienza a ser tomado en consideración como algo propio por los súbditos mismos". 5 Allí nace la idea de una esfera pública no vertical sino deliberativa.

Los procedimientos democráticos estatuidos en términos de Estado de derecho (...) permiten esperar resultados racionales en la medida en que la formación de la opinión dentro de las instancias parlamentarias permanezca sensible a los resultados de una formación informal de la opinión en el entorno de esas instancias, formación que no puede brotar sino de espacios públicos autónomos. Sin duda (...) el presupuesto de un espacio público político no hipotecado es un presupuesto carente de realismo; pero bien entendido, no se le puede calificar de utópico en sentido peyorativo. ${ }^{6}$

No es casual que Habermas refiera el término Estado de derecho como condición requerida para la existencia de una opinión pública libre y democrática. La cuestión es discutir si en el

3 MARTÍN-BARBERO, Jesús. "Ausencia de relato y desubicaciones de lo nacional", en VARIOS AUTORES. Imaginarios de nación. Op. cit., p. 19.

4 BOLADERAS, Cucurella. "La opinión pública en Habermas". Anàlisi 26. Barcelona: Universidad Autónoma de Barcelona, 2001, p. 68.

5 HABERMAS, J. Historia y crítica de la opinión pública. Madrid: Gustavo Gili, 1981, p. 71

6 HABERMAS, J. Facticidad y validez. Madrid: Trotta, 1998, p. 614. 
actual contexto venezolano gozamos de un Estado de derecho en sentido real, no virtual, que vaya más allá de lo que la Constitución y las leyes nos proclaman. El jurista mexicano Rodolfo Vázquez, en línea conceptual con J. Habermas y desde un punto de vista liberal, nos aclara qué es el Estado de derecho, cuando dice:

No todo Estado es estado de derecho, incluso más 'no todo estado con derecho es un estado de derecho'. Una de las características de los estados modernos es, precisamente, su organización a partir de un sistema jurídico que delimite funciones y que permita la resolución de conflictos en el seno de la propia sociedad. Sin embargo, esta vocación de legalidad puede ser perfectamente compatible con estados dictatoriales o autoritarios. La mera existencia empírica de un ordenamiento jurídico no garantiza ipso facto un estado de derecho. Para que éste sea posible se deben satisfacer cuatro condiciones internas que resumiría en las siguientes: 1 . primacía de la ley; 2 . respeto y promoción de los derechos fundamentales; 3. control judicial de constitucionalidad; y 4. responsabilidad de los funcionarios. Todas ellas condiciones necesarias y, en su conjunto, suficientes para que exista un estado de derecho, y no cualquier estado de derecho, sino (...) un estado liberal igualitario de derecho. ${ }^{7}$
No requerimos de intérpretes para entender y ver la ruptura que existe conceptualmente con la realidad y que la propia realidad nos está mostrando. La descripción del concepto de Estado de derecho es viva y bien clara. No hay lugar a dudas. No es casual que un editorial de la revista Sic, publicación confesional del Centro Gumilla de los jesuitas, dijera con mucha claridad y preocupación que:

Para un gobernante lo más imprescindible es la independencia de poderes. Recuérdese que ésta se diseñó, no en tiempo del absolutismo de la segunda mitad del siglo XVI y el siglo XVII sino en el siglo XVIII, cuando gobernaba lo que se llamó el despotismo ilustrado, cuyo lema era 'todo para el pueblo, pero sin el pueblo'. Esto es lo que no entendió el bloque soviético que denigró de la que llamó democracia formal y siguió aferrado a la línea del centralismo democrático, que acabó en pura y simple dictadura, o la del secretario general del partido o la de la nomenclatura. Esta fue una de las causas estructurales de su implosión. Esa exclusión de los otros se tradujo en pérdida de dinamismo, en distorsión, en esclerosis y por supuesto, en una violación sistemática de los derechos humanos. ${ }^{8}$

Finaliza de manera tajante, como conclusión, con esta idea:

7 VÁZQUEZ, Rodolfo. ¿Qué es el Estado de derecho? Un punto de vista liberal. México, D.F.: Instituto Tecnológico Autónomo de México, 2003, p. 223.

8 SIC. "La toma total del poder ¿es el mejor camino?" SIC. Año LXVIII, núm. 675. Caracas: Centro Gumilla, junio del 2005, p. 196. 
Para hacer la revolución, entendida ésta como reinventar un país destruyendo todo lo anterior y rediseñándolo completamente, es cierto que la toma total del poder es el mejor camino. Pero a estas horas de la historia, la pretensión de parar la historia, de negarla y de arrancar desde uno mismo es una pretensión absolutamente irracional y está condenada al fracaso. Pero no sólo al fracaso sino a dejar el país en ruinas y con traumas profundísimos. Quienes creen en el espejismo de reinventar un país sienten que el expediente de eliminar toda competencia es el más cómodo y expedito y por eso no ven problema. Sin embargo, para el que no quiera ser ciego, ya se está viendo cómo lo pretendidamente nuevo está empezando a ser una reedición de lo que todos rechazamos y por lo que Chávez llegó al poder.?

Cambiamos los actores, los símbolos para guiarnos, cambió el sentido de país y hasta los imaginarios, se voltearon las experiencias, pero la manera de conducir la "cosa pública" sigue igual y hasta de forma desquiciada y sin límites. Es que no tenemos idea ni realidad de Estado porque no hay transparencia en los actos gubernamentales. Nada ha cambiado en el panorama, aunque estemos en presencia de un paisaje distinto. José Ignacio Cabrujas, en conversación con la Comisión Presidencial para la Reforma del Estado Venezola- no, por allá en 1987, decía que en Venezuela el concepto de Estado es apenas un disimulo:

El concepto de Estado es simplemente un "truco legal" que justifica formalmente apetencias, arbitrariedades y demás formas del "me da la gana". Estado es lo que yo, como caudillo o como simple hombre de poder, determino que sea Estado. Ley es lo que yo determino que es Ley. Con las variantes del caso, creo que así se ha comportado el Estado venezolano, desde los tiempos de Francisco Fajardo hasta la actual presidencia. (...) El país tuvo siempre una visión precaria de sus instituciones porque, en el fondo, Venezuela es un país provisional. (...) El Estado venezolano actúa generalmente como una gerencia hotelera en permanente fracaso a la hora de garantizar el confort de los huéspedes. Vivir, es decir, asumir la vida, pretender que mis acciones se traducen en algo, moverme en un tiempo histórico hacia un objetivo, es algo que choca con el reglamento del hotel, puesto que cuando me alojo en un hotel no pretendo transformar sus instalaciones, ni mejorarlas, ni adaptarlas a mis deseos. Simplemente las uso. (...) El resultado es que durante siglos nos hemos acostumbrado a percibir que las leyes no tienen nada que ver con la vida. (...) La estructura principista del poder fue siempre nuestro mejor escenario. ${ }^{10}$

9 Ibídem.

10 CABRUJAS, José Ignacio. "El Estado del disimulo", en VARIOS AUTORES. Heterodoxia y Estado. Caracas: Comisión Presidencial para la Reforma del Estado, 1987, p. 7 y ss. 


\section{De la "no cultura" y la "no comunicación"}

La idea la tomamos de la simbolización que plantea el antropólogo francés Marc Augé cuando expresa en términos del "no lugar", de que el "no lugar" es lo contrario de un domicilio, de una residencia, de un lugar en el sentido corriente del término. "Sólo, pero semejante a los demás, el usuario del no lugar mantiene con éste una relación contractual simbolizada por el billete de tren o de avión, la tarjeta para el peaje, etc. En estos no lugares se conquista el anonimato si se provee la prueba de la identidad personal...". ${ }^{11}$ Y más adelante, el texto nos sigue diciendo de manera conclusiva que "El espacio del no lugar no crea ni identidad singular ni relación, sino soledad y similitud". Creo que es posible agregar a esta idea otra dimensión -de orden cultural y comunicacional- relacionada con el momento que está atravesando el país.

Con la muerte de Gómez el país entra en una onda modernizadora que in- tenta llegar a todos los rincones del territorio. Alguien decía "que el país se lanza a la conquista tumultuosa de la modernidad". La cultura no podía quedar atrás y no se quedó. Desde el sector público, en donde la figura de Mariano Picón Salas es cita y parada obligada, hasta el espacio privado con la creación de fundaciones e iniciativas privadas, la cultura empieza a adquirir el estatuto que ella se merece. ${ }^{12}$

Sin embargo, a partir de 1999 se inicia todo un proceso de "ordenación" y de "redefiniciones" que dan al traste con muchas equivocaciones cometidas y seguramente no asumidas, pero también con muchos logros que no es el caso enumerar y detallar. ${ }^{13}$ Con el triunfo de Hugo Chávez Frías y el desmoronamiento de la sociedad política tradicional y dominante por un poco más de cuarenta años, se abre un terreno fértil para la "refundación del país", como anunciara el mismo presidente después de la aprobación de la nueva Constitución. Y en ese camino andamos...

11 AUGÉ, Marc. Los "no lugares". Espacios del anonimato. Una antropología de la sobremodernidad. Madrid: Gedisa, 1996, p. 83.

12 Recomendamos la lectura del excelente trabajo, analítico y descriptivo, de la historia del quehacer cultural venezolano: "Hacer cultura y dar cultura: inventario de una heterogeneidad", de Moraima Guanipa, en VARIOS AUTORES. Venezuela siglo XX. Visiones y testimonios. Caracas: Fundación Popular, 2001.

13 PINO ITURRIETA, Elías et al. Historia mínima de Venezuela. Caracas: Fundación de los Trabajadores de Lagovén, 1992; La cultura de Venezuela. Historia mínima. Caracas: Fundación de los Trabajadores de Lagovén, 1996; J. VELÁSQUEZ, Ramón. Balance del siglo XX. Caracas: Fundación Francisco HerreraLuque/Grijalbo, 1996. 
La política, o una concepción de la política, fue irradiando todos los espacios y rincones de la vida del país. Incluso, la calle no quedó exenta de esa dinámica. Así, el campo de la cultura y la comunicación han sido también lugares de la política. La representación gubernamental de esas dos instancias lo expresa de manera visible a través de las palabras que ya se traducen en acciones. El ministro de la Cultura Francisco Sesto recién asumía el cargo y lo decía: "El Ministerio de la Cultura se constituirá como un órgano con cartera, con funciones políticas y estratégicas". Y el ex ministro de Comunicación e Información Andrés Izarra fue elocuente: "Estamos en una guerra ideológica". De esta manera apreciamos cómo el actual Estado tiene claridad sobre la significación estratégica de la cultura y de los medios de comunicación.

La economía también está jugando en este proceso, aunque para ser precisos siempre juega, pero en este tiempo la economía juega a favor del gobierno por los altos precios petroleros y por la aparente recuperación económica que ello ha significado.

Está armado el círculo. La dinámica económica y política en la trama de decisiones, en la formulación de políticas de todo orden y niveles, involucra necesariamente una cuestión cultural que nos remite inmediatamente al imaginario en que se mueve el poder, en este caso el "gobierno revolucionario y bolivariano" hoy en funciones de Estado. Esas dos dimensiones son fundamentales para entender todo un conjunto de decisiones intelectuales y políticas como líneas de acción cultural que intentan proyectarse en el tiempo histórico y convertirse, como decía un dirigente del alto gobierno, en "referencia y en poder hegemónico". En ese sentido, hay que entender el gran esfuerzo que están haciendo los más diversos "actores políticos" del llamado "oficialismo" para la reinstitucionalización y la reconstrucción del Estado, de la polis, de la comunidad política y cultural, de la ciudadanía y de la sociedad en general.

Lo que sí ha quedado claro en estos ya casi seis años del "proceso" es la evidencia de una razón muy vieja en América Latina y en el pensamiento de una "izquierda política" anclada en la nostalgia y el pasado, que además ha conducido a fracasos estrepitosos, que carga de sentido positivo la estatización de cualquier actividad pública por encima de las iniciativas libres de la ciudadanía heterogénea, plural y caótica que reside en la mal llamada sociedad civil o en la sociedad en general. Es la idea del Estado como concepción "iluminada" o "vanguardista" que debe estar por encima como una especie de "superpoder" o big brother orwelliano orientando los designios hacia dónde debe conducirse la sociedad. No es más que el deseo de fortalecimiento de una idea errónea de la esfera públi- 
ca contra el poder "incontrolado" e “incontrolable?” de los intereses privados. Aquí reside la confusión entre lo público y lo estatal-gubernamental, la confusión en que el ámbito de la democratización de la sociedad debe darse desde el Estado y su institucionalidad y no desde las fuerzas que deben renacer en el interior de la propia sociedad.

Ese planteamiento, quizás excesivamente principista, nos sirve para entender cómo se ha ido dando en el actual gobierno la toma de decisiones en forma de políticas públicas hacia el sector de la cultura y la comunicación. Desde ese marco quizás podamos ver claro cuál ha sido la relación entre la política económica (activa e interventiva) que se refleja en la Ley de Presupuesto Nacional y la política de cultura y comunicación que se proyecta en las acciones concretas.

La politica cultural y comunicacional en la Venezuela del presente es de gran significación para el poder. Aunque la idea de política no está claramente definida en ningún documento de la actual gestión tanto en cultura como en información-comunicación; ella se puede extraer desde las declaraciones y retórica tanto del Presidente de la República como de los funcionarios de turno en los respectivos despachos ministeriales. Así, y a manera de ejemplo, Francisco Sesto -ministro de Estado para la Cultura y presidente del Consejo Nacional de la Cultura- ha venido diciendo repetidamente que:

\begin{abstract}
Debemos refundar la institucionalidad hecha a lo largo del siglo XX, pero construida por sumatoria y no está adecuada a los tiempos que vivimos (...). En ese sentido, la necesidad de reformular leyes y reglamentos relativos a la cultura y de crear algunas leyes que están faltando: la Ley Orgánica de la Cultura, la Ley de Gerencia de Gestión Pública de la Cultura y la Ley de Financiamiento Cultural (...). Hay que someter los instrumentos jurídicos vigentes a una cuidadosa y profunda revisión para adecuarlos a los tiempos actuales. Crearemos las plataformas necesarias para llevar adelante desde el Estado, la universalidad de las manifestaciones culturales venezolanas. Finalmente, se afianzarán los valores necesarios para llevar adelante el proyecto contenido en la Constitución Nacional. ${ }^{14}$
\end{abstract}

No hay ninguna línea ni declaración que nos explique la idea de que toda política cultural, si bien requiere de la presencia del Estado y del capital en la cultura, solo podrá cumplir objetivos de democratización e inclusión si ella se guía por "criterios de igualdad, acceso, servicio público, descentralización, participación, autonomía y ruptura de roles jerárquicos entre industria, creadores y usuarios".

Por su parte, desde el espacio de la información y la comunicación tampoco encontramos una idea clara sobre el referente de una auténtica y verdadera 
política comunicacional. Todas las expresiones del alto gobierno encabezadas por el propio Presidente de la República van orientadas hacia el desprestigio de los grandes medios por la sospecha hacia ellos, evidente desde los de Frankfurt, en cuanto industrias y "aliados del neoliberalismo salvaje". La idea expresada explícitamente es la de dar origen a una "auténtica comunicación" no contaminada por las industrias culturales.

Dentro de ese contexto emergente la idea de configurar un país distinto - ¿si no a qué viene la publicidad de "Venezuela ahora es de todos"?- está más que comprometida. De ahí la sugestiva expresión de Augé acerca del no lugar llevada a la dimensión de la cultura y la comunicación. El no lugar es otra concepción de la cultura y la comunicación -es la no cultura y la no comunicación- que se expresa en una cosmovisión de vida y de existencia, por lo tanto, en una perspectiva de sujeto social, que niega la propia identidad en cuanto percepción y pertenencia a una historia, a un proyecto de país, a una idea de democracia y libertad, a unos relatos y vivencias. Porque "Si un lugar puede definirse como lugar de identidad, relacional e histórico, un espacio que no puede definirse ni como espacio de identidad ni como relacional ni como histórico, definirá un no lugar". ${ }^{14}$

\section{La realidad de los medios y el periodismo}

Vamos a detenernos ahora en la realidad de la comunicación y la información, así como en sus gestores, para entender cómo el actual Estado interfiere en esa esfera y así comprender el sentido y la implicación de sus acciones.

Antes de 1998 -esa será la fecha emblemática que todos nombremoslos distintos partidos políticos se "quiebran" en el sentido de su representatividad frente a la sociedad:

\begin{abstract}
... también la pérdida de los lugares de intercambio con la sociedad, el desdibujamiento de las maneras de enlace, de comunicación de los partidos con la sociedad produce su progresivo alejamiento del mundo de la vida social, hasta convertirse en puras maquinarias electorales cooptadas por las burocracias del poder. ${ }^{15}$
\end{abstract}

Los sondeos de opinión de aquel entonces lo venían asomando y ya los distintos grupos políticos dejaban de ser el espacio de mediación que habían sido tiempo atrás, ahora se topaban con otra o con otras formas de mediación que implicaba, sino una disolución de la política, una nueva constitución en la trama de la política con la presencia de actores nuevos que están representados por las pantallas de televisión, los micrófonos de la

14 AUGÉ, Marc. Op. cit., p. 83.

15 MARTÍN BARBERO, Jesús. Op. cit., p. 83. 
radio, las páginas de los periódicos y los productores simbólicos de esos medios.

Este no es un fenómeno exclusivamente nuestro, es una ola que se mueve a lo largo del planeta en donde los partidos viven una profunda crisis de representatividad y no solo por la corrupción ante el poder, sino por la massmediación que ha establecido un "nexo simbólico" distinto al que venía proponiendo y estableciendo el partido.

Quizá la política no sea ya lo que imaginábamos hasta hace poco que era, y la gente no está dispuesta a seguir invirtiendo tiempo y energía en los ritos de marcha, la concentración y el desfile o los actos de identificación colectiva. Es probable que al aumentar los niveles educacionales de los ciudadanos y extenderse la comunicación de imágenes televisadas, al enfriarse la contienda ideológica y dilatarse los derechos del individuo, al perder gravitación los partidos y diversificarse los derechos de la gente, la política cambie de ubicación y sentido. ${ }^{16}$

El país ha sido, y lo es todavía, un excelente laboratorio de todos los cambios que ha sufrido la política, el partido, la trama discursiva de la que está hecha la actual representación política y el papel que la ciudadanía le asignó a los medios y sus periodistas.
En todo este tiempo los distintos medios, y un buen grupo de comunicadores sociales, se han venido comportando como actores políticos y no solo como espacio público para la competencia política. Los medios no solo han sido narradores de los distintos aconteceres sociales y políticos, tampoco se han limitado a ser comentaristas de los hechos, sino que han sido participantes muy activos del conflicto político: “... son actores políticos de primer rango por la variedad y la potencia de los recursos de que disponen para influir y lucrar en todos los escenarios posibles". ${ }^{17}$ Ciertamente, no se trata de la representación de su mejor papel, pero lo han venido representando y además asumiendo con todas las consecuencias del caso para la audiencia y para el ejercicio del "campo periodístico". Hemos dicho muchas veces que la sociedad del presente no puede ser pensada, y ni siquiera imaginada, sin la comunicación. Es más:

Sería difícil imaginar una democracia contemporánea sin medios de comunicación, pero a la par, el fortalecimiento democrático en América Latina, visto especialmente desde el contexto venezolano, pasa por establecer reglas de juego para que este poder mediático sea ejercido con una mayor transparencia por parte

16 Brunner, citado por MARTÍN BARBERO, Jesús. Op. cit., p. 78.

17 BORRAT, Héctor. El periódico, actor político. Madrid: Gustavo Gili, 1989, p. 159. 
de empresarios y periodistas, a la par de abrir cauces para la acción ciudadana. ${ }^{18}$

Pues bien, en esta sociedad a la que el investigador francés Jean Mouchan llama "república de los medios", los mismos medios han sido actores bien privilegiados en el conjunto de actores sociales, incluso han sido actores muy celosos del "movimiento de la cosa pública”. Al final, después de todo lo que hemos vivido los venezolanos, los medios y sus periodistas y sus formas de actuación quedaron "al desnudo, expuestos a una prueba de la verdad de resultados inciertos". 19

La crisis de algunos actores centrales del campo periodístico ha puesto de manifiesto la necesidad de repensar la información periodística en relación con la vida pública y con el funcionamiento de la democracia en las sociedades de capitalismo avanzado. La actividad de los medios de comunicación se ha convertido en una de las piezas más dinámicas de la industria cultural y, más importante aún, en un factor clave de la estructuración de la vida social y política. La constatación de este hecho social fundamental es razón más que suficiente para situar el campo periodístico en un lugar preferente dentro de la reflexión crítica. ${ }^{20}$
El informe del Programa de las Naciones Unidas para el Desarrollo (PNUD) del 2004, que lleva por título La democracia en América Latina, nos recuerda que los medios son un poder, no solo poder comunicativo, sino también poder político. Según ese informe los medios, junto con la Iglesia, los sindicatos, los organismos multilaterales como el FMI y los empresarios privados constituyen un "poder real" más allá del que tradicionalmente se les venía asignando. Hoy los medios, según la tesis de Luhmann, se nos presentan como un sistema operativo autónomo. Es decir, "un verdadero sistema social, una conquista evolutiva propia del mundo contemporáneo y en efecto del proceso universal de diferenciación de la sociedad". ${ }^{21}$ No resulta casual, entonces, que el PNUD emplee la categoría de poder fáctico para referirse a los medios en cuanto poder que hoy legitima y explica otras formas clásicas de poder que van desde el poder económico, el poder político y el poder coercitivo.

En el trasfondo de ese planteamiento irrumpe el hecho de que el poder comunicativo y el poder político de los medios les ha permitido tener una presencia determinante, incluso decisiva y

18 CAÑIZÁLEZ, Andrés. "El poder real". SIC. Año LXVII, núm. 666. Caracas. Centro Gumilla, julio del 2004, p. 269.

19 MOUCHAN, Jean. Política y medios. Los poderes bajo influencia. Barcelona: Gedisa, 1999, p. 123.

20 ZELLER, Carlos. "Los medios y la formación de la voz en una sociedad democrática". Anàlisi 26. Barcelona: Departamento de Periodismo y Ciencias de la Comunicación de la Universidad Autónoma de Barcelona, 2001, pp. 123-124.

21 LUHMANN, Niklas. La realidad de los medios. Barcelona: Iberoamericana/Anthropos, 2000, p. X. 
definitiva, en la constitución conflictuada del país. Al punto de que esa injerencia de los medios y de la información periodística modificó la cultura profesional de los periodistas y hasta la cultura receptiva y perceptiva de las audiencias.

Por otro lado, ante la presencia de un proceso político como el que describimos al inicio del texto, y que seguramente me habré quedado corto no solo por mis apreciaciones sino porque la dinámica del gobierno y la del propio Presidente están en "pleno desarrollo" y en escalada creciente, cabría preguntarse de manera obligatoria cuál debería haber sido la actitud de los medios y los periodistas en el contexto actual, en el que el desafío es el de la libertad y la democracia, el del progreso y la modernización del país, el de la racionalidad del bien público por encima de intereses particulares y del poder.

Cantidad de preguntas nos asaltan sobre este tema de los medios, los periodistas y su comportamiento. Las respuestas son múltiples y quizás ninguna nos sirva para entender este amasijo de hierros retorcidos en que se ha convertido la Venezuela del presente. Así, desde los inicios de esta etapa política del país es perfectamente visible la configuración de un mapa de escaladas discursivas y de acciones políticas, de un lado y del otro, que nos han llevado a esta situación. En ese sentido, siempre recuerdo aquello que escribiera el filósofo español Julián Marías en un texto colectivo del 2001, en donde se trataba de explicar y entender por qué se había llegado a la guerra. Nos decía:

Habría que preguntarse desde cuándo empieza a deslizarse en la mente de los españoles la idea de la radical discordia que condujo a la guerra. Y entiendo por discordia no la discrepancia, ni el enfrentamiento, ni siquiera la lucha, sino la voluntad de no convivir, la consideración del "otro" como inaceptable, intolerable, insoportable (...). La guerra fue consecuencia de una ingente frivolidad. Esta me parece la palabra decisiva. Los políticos españoles, apenas sin excepción, la mayor parte de las figuras representativas de la Iglesia, un número crecidísimo de los que consideraban "intelectuales" ( $y$ desde luego los periodistas), la mayoría de los económicamente poderosos (banqueros, empresarios, grandes propietarios), los dirigentes de sindicatos, se dedicaron a jugar con las materias más graves, sin el menor sentido de responsabilidad, sin imaginar las consecuencias de lo que hacían, decían u omitían. La lectura de los periódicos, de algunas revistas "teóricas", reducidas a mera política, de las sesiones de las Cortes, de pastorales y proclamas de huelga, escalofría por falta de sentido de la realidad, por su incapacidad de tener en cuenta a los demás, ni siquiera como enemigos reales, no como etiquetas abstractas o mascarones de proa. ${ }^{22}$ (Las cursivas son nuestras)

22 MARÍAS, Julián. Ser español. Ideas y creencias en el mundo hispánico. Barcelona: Planeta, 2001. 
Se me dirá que esas comparaciones no son muy útiles en la perspectiva, como alguien una vez nos increpaba, de que una cosa es el "espíritu del venezolano" y otra muy distinta el "espíritu español". Pero es que las situaciones son tan parecidas y tan polarizadas que la tentación a la comparación es muy grande. Aunque la situación no es la misma que vivimos en momentos críticos como la huelga del 2 de diciembre del 2001, la intentona golpista del 11 de abril del 2002, la del paro cívico y petrolero entre el 2002 y el 2003, la guarimba de febrero de 2004 y todas las tensiones vividas previas al referendo revocatorio del mandato presidencial y luego los resultados del referendo..., sin embargo, nuestra democracia sigue estando amenazada por ese conflicto de la polarización que lejos de desaparecer se ha ido tornando un "gigante dormido" en estos momentos. Pero allí está. El sociólogo alemán Juan Linz se refiere así a este tema:

Problemas insolubles, una oposición desleal dispuesta a explotarlos para desafiar al régimen, el deterioro de la autenticidad democrática entre los partidos que apoyan al régimen y la pérdida de eficacia, efectividad (especialmente ante la violencia) y, por último, de legitimidad, llevan a una atmósfera generalizada de tensión, a una sensación de que hay que hacer algo que se refleja en un aumento de la politización. Esta fase se caracteriza por la circulación de rumores, el aumento de la movilización en las calles, violencia anómica y organizada, tolerancia o justificación de algunos de estos actos por algunos sectores de la sociedad y, sobre todo, un aumento de presión por parte de la oposición desleal. La predisposición a creer en conspiraciones y la rápida difusión de rumores, algunas veces fomentados por los límites impuestos a los medios de comunicación al tratar de controlar la situación, contribuyen a una incertidumbre y a una imposibilidad de hacer previsiones que puede llevar a un empeoramiento de crisis económicas. ${ }^{23}$

Pero volvamos al campo periodístico y a las industrias comunicativas. Ya dijimos que en todo este devenir del país de los últimos tiempos, el campo de la massmediación ha sido un lugar de la política y de los aconteceres políticos. El escritor Ibsen Martínez nos indica que todo ese fenómeno tiene un devenir que se remonta a dos décadas atrás, cuando los tiros de los medios y algunas de sus figuras más prominentes se dirigieron hacia el desprestigio de la democracia representativa, la política y los políticos; aunque la sociedad política del país también tuvo su parte de responsabilidad. Y concluye el escritor diciéndonos:

... que el efecto neto de aquella campaña de años fue que cuando hicieron falta diestros políticos de prestigio y oficio para oponerlos a la avasallante demagogia

23 LINZ, Juan. La quiebra de las democracias. México: Patria, 1990, p. 132. 
electoral del prodigioso agitador que es Hugo Chávez, ya era demasiado tarde: los medios los habían desacreditado inmisericordemente, por completo y sin contemplaciones. $^{24}$

Así que cuando el actual Presidente resulta electo en los comicios del 6 de diciembre de 1998 las dimensiones del poder comunicativo y el poder político se visibilizan de manera más brutal en el sentido de aquello que dijera el propio Chávez en el día del periodista del año 2001: "... he sostenido un complejo sistema de relaciones con los medios de comunicación (...) como parte de un choque histórico de fuerzas". Se abría desde ese momento una confrontación prolongada entre medios y gobierno. Podemos señalar de manera más bien puntual los elementos conceptuales y de realidad característicos de esta confrontación:

- Este gobierno en funciones de Estado tiene conciencia y claridad sobre la significación estratégica de los medios de comunicación en el "hacer de la política posmoderna".

- Ese hecho se complementa con aquella idea que esbozaban los "intelectuales orgánicos" del gobierno de Getulio Vargas en el Brasil de 1934 a 1945, cuando afirmaban que
"Los medios de comunicación no deben pensarse como 'simples medios de diversión', sino como armas políticas sometidas al control de la razón del Estado". ${ }^{25}$

- Sin embargo, ese planteamiento hay que verlo con cierto cuidado y sentido acerca de la omnipotencia mediática convertida en cultura de masas. Nuevamente Ibsen Martínez nos da la clave:

En el amasijo ideológico que da forma al discurso de Chávez y los suyos destaca la idea de atribuir a los medios radioeléctricos poderes demiúrgicos y decisivos para el desenvolvimiento de la sociedad. Ese discurso, desde luego, resulta tramposo por ambivalente... ${ }^{26}$

- Dentro del rol que el gobierno le asignó a los medios como "armas políticas" (no hay más que ver el conjunto de medios del gobierno al servicio de un grupo) se han venido desarrollando dos estrategias: por un lado, la necesidad política de contrarrestar la acción de la libertad de expresión de los medios privados con leyes sumamente restrictivas y fiscalizadoras de los contenidos (este será el momento presente); y por el otro, el hostigamiento del mismo gobierno a través

24 MARTínEZ, Ibsen. "La televisión de señal abierta y sus consensos". El Nacional. Caracas, 13 de setiembre del 2004, p. A-9.

25 ORTIZ, Renato. "Brasil: sociedad, cultura y nación", en VARIOS AUTORES. Imaginarios de nación. Bogotá: Ministerio de la Cultura de Colombia, 2001, p. 63.

26 MARTÍNEZ, Ibsen. Op. cit. 
del discurso presidencial y las cadenas de radio y televisión y el hostigamiento redentor de los cercanos y afectos al proceso (momento más fuerte en años atrás, especialmente entre el 2002 y el 2003).

- En este rápido mapeo de situación, dos aspectos debemos destacar a través del puente de las palabras de periodistas en ejercicio profesional. Esos periodistas se refieren, tratando de mantener el equilibrio, a la actuación del campo periodístico y a las rutinas periodísticas aprendidas y hasta impuestas algunas durante todo este tiempo. Para el primero de esos periodistas el hecho es que:

... las prácticas, discutibles, poco edificantes o del todo incorrectas, en las que incurrió en su conjunto la prensa venezolana durante el apogeo de una crisis sociopolítica a la que, por cierto, también le falta desenlace, no tendrían que haber sido una consecuencia necesaria de la toma editorial de partido ante las disyuntivas que trajo consigo el ascenso al poder de Hugo Chávez Frías. Sino que se trataron de las manifestaciones más patológicas, agudizadas por un ambiente pernicioso, de falencias crónicas que el ejercicio del periodismo venía arrastrando en este país desde mucho antes (...). Justamente desde hace 30 años se empezó a notar en los medios venezolanos un verdadero descalabro de toda estructura de supervisión (que no fuera la mera censura de línea editorial) y tutoría. Acháquesele a lo que se quiera, a la política de reducción de costos en la plantilla, a la migración constante de talentos fogueados hacia las actividades corporativas, a una brecha generacional que llevó a los novatos rebeldes a despreciar de manera tajante todo lo que hacían sus predecesores. Pero lo incuestionable es que la figura del maestro, encarnada en el reportero veterano o en el gerenteinductor, prácticamente desapareció de las redacciones locales para ser suplantado por personal de recolección de notas y cerrado de espacios. Sin supervisión didáctica, sin feedback oportuno, experto y de primera mano, las malas prácticas no sólo se colaron, sino que incluso llegaron a consagrarse como las correctas o, al menos, las rutinarias. Y en este vacío de self-made-men hechos a su mejor entender y con torceduras congénitas (a veces éticas, a veces redaccionales o de otra índole) que nunca encontraron corrección, ni pensar en la posibilidad de tejer redes que permitan hacer coberturas regulares de carácter interdisciplinario acerca de temas que, sin duda, sólo podrían abordar a cabalidad de esa manera. Se me dirá que estoy hablando del período en que la prensa derrocó a un presidente, destapó cientos de escándalos y aupó más de un liderazgo. Pero esos hitos históricos creo que apuntalan una relación de inversa proporcionalidad: a mayor relevancia política de los medios venezolanos, menor el esmero que pusieron en el robustecimiento de sus prácticas profesionales. ${ }^{27}$

27 SCHARFENBERG, Ewald. "Periodismo venezolano. De un esplendor supuesto al raquitismo". Comunicación 131. Caracas: Centro Gumilla, tercer trimestre del 2005. 
Para el segundo, el hecho es que los periodistas y los medios han venido perdiendo credibilidad y para ello se reclama una vuelta al periodismo porque:

Hoy en día el periodismo no es una profesión, es un puesto de combate; y la información no es un insumo para comprender lo que vivimos, sino un arma para hacer propaganda (...). El papel de los periodistas no es proclamar a quiénes no les interesa su visión del desarrollo del mundo. Es posible pertenecer a la oposición, o tener la posición política que nuestras convicciones nos indiquen respetando los parámetros y principios rectores de este oficio. Montar ollas, colocar titulares apócrifos a conciencia, repetir una información infundada, no conceder la réplica, no pedir disculpas, son faltas muy graves a la ética profesional, tanto como si un psiquiatra se sentara a beber cerveza y a comentar en voz alta las confesiones de sus pacientes. Son errores que le hacen un enorme daño al ejercicio democrático que algunos dicen estar defendiendo. En Venezuela se han dicho cosas insólitas en nombre de la defensa de la libertad. Acá se ha dicho, por ejemplo, que el soldado Pedreañez fue asesinado por agentes del G-2 cubano. Hace varios meses un periódico especializado y una columnista muy conocida deslizaron que el gobierno estaba involucrado en los atentados de AlQaeda en Madrid. Varios especialistas denunciaron simultáneamente una invasión de libios por Margarita y de guerrilleros colombianos por los Andes, integrantes de una fulana "Operación Tenaza". El año pasado se puso de moda la denuncia de una misteriosa nacionalización de chinos en el Registro Electoral, sobre la cual, súbitamente, no se dijo más nada. Hace dos años la prensa levantó una lamentable olla folletinesca con el asunto de los Comacates, unos fulanos militares alzados que anunciaban los detalles de un golpe de estado por correspondencia. Los Comacates desaparecieron cuando dejaron de ser útiles. El año pasado se dijo que el cura Calderón fue secuestrado por el gobierno, una denuncia que el mismo Calderón se encargó de desmentir cuando fue liberado. Se ha dicho que PDVSA está llena de cubanos, que los libios están en Barrio Adentro, que Osama Bin Laden es amigo de Chávez, que las FARC están en Caracas. Acá se invoca, de forma ramplona e ignorante la defensa de la democracia cuestionando las relaciones del gobierno con los países de la OPEP, se apela a troche y moche, sin saber qué es, el "eje de mal” que prescribió George Bush al resto de la humanidad. Al finalizar el paro, cuando el gobierno recuperó la producción petrolera y le anunció a sus clientes el fin de los motivos de "fuerza mayor" que impedían la venta del crudo en los mercados internacionales, los medios de comunicación no dijeron nada. De eso nos enteramos por una cadena. El fanatismo y la promoción de supercherías le han hecho un flaco servicio a la causa de la oposición (...). Ni los presidentes, ni los jueces, ni los gobernadores, ni el clero, ni el estamento militar son intocables en el ejercicio democrático. Tampoco lo son los medios. Todos son actores de la sociedad indispensables que tienen una responsabilidad pública. La rectitud en el proceder no es un asunto reservado sólo a los cargos del gobierno. Llegará el mo- 
mento en el cual empresarios, animadores, locutores, periodistas, jefes de información, editores y reporteros se hagan una autocrítica e inicien, por su propio bien, un diálogo honesto y civilizado con el resto de la sociedad sobre lo que ha pasado en este país en los últimos dos años. $^{28}$

- El tema de la libertad de expresión, aunque mejor y más preciso es el concepto de libertad de información, y el ejercicio del derecho a la información subyacen en todo este debate que se ha venido gestionando casi desde el principio de este gobierno. El gobierno, y es un hecho cierto y evidenciable en todo este tiempo, ha venido diciendo por todos los rincones de la escena nacional e internacional "que en este país hay un absoluto respeto a la libertad de expresión. Aquí no hay medios clausurados o censurados, aquí no hay periodistas presos o censura de información...".

El problema no radica allí solamente, o ese no es el único indicio de la existencia de libertad de expresión o de información. Hay mecanismos sutiles, y otras veces no tanto, que van desde agresiones directas a comunicadores; el uso indiscriminado de las "cadenas"; las men- ciones denigrantes o intimidatorias contra los medios; la inacción de las autoridades ante las agresiones; los ataques violentos contra medios; el uso de recursos administrativos como medidas de presión; el impulso a legislaciones restrictivas y de supervisión; la desatención a medidas cautelares expedidas por la Comisión Interamericana de Derechos Humanos; los atropellos cometidos por subordinados del Poder Ejecutivo; la dificultad de acceso a fuentes oficiales; el retiro de publicidad a medios no afectos al gobierno; los ataques contra la reputación de periodistas; las amenazas a periodistas; la limitación contra fuentes extranjeras de visita en el país y el sesgo informativo en medios del Estado... ${ }^{29}$ que ponen en duda el ejercicio de esa libertad como derecho humano fundamental, al punto de que la Organización de las Naciones Unidas la tiene por "la piedra de toque de todas las libertades a las cuales están consagradas las Naciones Unidas" y por "un factor esencial -como dice la propia ONU- de cualquier esfuerzo serio para fomentar la paz y el progreso del mundo". La presencia de esos hechos limita visiblemente el ejercicio de los periodistas y los medios, pero también la

28 MOLEIRO, Alonso. "Traigan de vuelta al periodismo". Comunicación 127. Caracas: Centro Gumilla, 2004.

29 Véase al respecto el Informe Reporteros Sin Fronteras (2002-2003). Chávez y los medios: Del dicho al hecho. Toda esa enumeración de hechos puede verse allí con profundidad de detalles. 
garantía del derecho a estar bien informados, y, en último término, ponen en entredicho las propias libertades políticas.

Si hemos de referirnos a los inductores de la comunicación pública, no deja de ser sorprendente que ningún gobierno en los 45 años de democracia ha logrado concitar la animadversión de tantos periodistas y comunicadores de izquierda o derecha, afiliados o no al Colegio Nacional de Periodistas y al Sindicato Nacional de Prensa, por la forma de obstaculizar el acceso de la información del Estado y por las tácticas de amedrentar y agredir a los profesionales en la calle por medio de grupos afectos al gobierno. ${ }^{30}$

El periodista Hugo Prieto, al escribir acerca de lo que se llamó "la sentencia del magistrado Cabrera", es decir, la Sentencia 1013, decía que "lo único que puede ayudar a que haya libertad de expresión es que a la libertad la dejen expresarse o que a la expresión la dejen en libertad, y eso vale también, por supuesto, para los medios de comunicación, sin que intente ser ni-ni: imposible".

- Lo anterior se empata con otro signo que empieza a reflejarse en la situación periodística del presente: la amenaza de la autocensura. Ya la
Ley Orgánica de Telecomunicaciones, aprobada en junio del año 2000, abría las puertas al impulso de normas jurídicas que irían a "controlar" a los medios, especialmente a los radioeléctricos, y a establecer evidentes índices de autocensura en el mediano y en el largo plazos. Nos estamos refiriendo a los artículos 208 y 209 que pautan la "necesidad" de establecer supervisión sobre los contenidos de las transmisiones de radio y televisión. De allí se desprendió la Ley de Responsabilidad Social en Radio y Televisión que configura un menú de restricciones, tanto a los contenidos de entretenimiento como de información, en donde el término que mejor define ese instrumento es el del control: control jurídico, control político, control gubernamental y control constitucional. Y qué decir de la reforma al Código Penal, en donde se pone en evidencia, de manera groseramente transparente, la presencia de todo un articulado que revive las llamadas "leyes de desacato y de difamación civil y criminal". Muchos especialistas en el tema han dicho que este tipo de leyes son anacrónicas. Así, el Comité Mundial para la Libertad de Expresión plantea de forma tajante "que

30 AGUIRRE, Jesús María. "La credibilidad en juego". SIC. Año LXVII, núm. 666. Caracas: Centro Gumilla, julio del 2004, p. 261. 
las leyes de difamación criminal establecen sanciones penales por injuria (difamación oral) y libelo (difamación escrita). Los dos tipos de leyes, a menudo, son justificadas para abusos de la libertad de expresión. Sin embargo, los abusos reales ocurren cuando los funcionarios gubernamentales usan tales leyes para castigar a sus críticos o encubrir mala conducta (la corrupción, por ejemplo). La pena por decir 'lo que no se debe' es prisión, multa o ambos.

... junto a la Ley de Responsabilidad Social de Radio y Televisión contribuye con un clima de autocensura ante la posibilidad de aplicación de sus disposiciones. Esta consecuencia, difícil de cuantificar y medir, tiene una repercusión directa en el vigor del debate político y reduce significativamente los poderes de las personas para fiscalizar la acción estatal. ${ }^{31}$

Toda una armazón que conmina al periodista a limitarse en su ejercicio profesional por el temor o el miedo, que lleva a una escalada de mayores confrontaciones y raras veces a la resolución de los conflictos y las diferencias. En ese sentido, aquel principio de la democracia que tiene que ver con la transparencia del poder y el adecuado control por parte de la ciudadanía se tambalea peligrosamente. Porque la democracia supone como principio:

El desarrollo de una prensa crítica, o de cualquier otro medio informativo, se constituye como premisa básica de cualquier estado democrático y liberal. A mayor racionalidad mayor democracia y a menor racionalidad menor democracia. Sin embargo, este ideal choca con lo que J. Habermas ha llamado la 'refeudalización de la opinión ciudadana' (...). La información, lejos de ser veraz, objetiva e imparcial se impone bajo el velo de una política secreta de los interesados: se halla ideologizada. ${ }^{32}$

- Finalmente, está el tema de los medios gubernamentales que deben ser, por propia definición, medios del Estado. El conjunto de medios que configura la plataforma mediática del gobierno se ha convertido en la voz del poder y cada vez más alejados de la utopía de que ellos deben ser medios de servicio público. Durante este gobierno, lo que ya venía del pasado, se ha hecho patente la degradación de la idea de servicio público en los medios, sin diferenciar entre servicio público y brazo informativo y contrainformativo del gobierno-Estado. Las miserias de la información, como son la falsedad y

\footnotetext{
31 CORREA, Carlos y Yubi CISNEROS. "La libertad de expresión en la reforma del Código Penal". Comunicación 130. Caracas: Centro Gumilla, segundo trimestre del 2005, p. 6.

32 VÁZQUEZ, Rodolfo. Op. cit., p. 241.
} 
el sesgo, se han hecho presentes en las ondas radioeléctricas de los medios del actual Estado.

Para reforzar ese escenario el gobierno ha emprendido todo un "proyecto bolivariano de comunicación e información" que se fundamenta en lo que han llamado "ejes comunicacionales". Uno de esos ejes, el pilar fundamental en palabras del mismo gobierno, lo constituye el proceso de modernización y actualización de Venezolana de Televisión. Para el año 2004 VTV contaba apenas con menos de 20 estaciones repetidoras y llegaba solo al 67 por ciento de la población. La meta es alcanzar para este año 2005 a más de 47 transmisores activos y llevar la señal al 90 por ciento del territorio nacional y al 98 por ciento de la población. Los otros aspectos por considerar dentro de este reforzamiento de la política comunicacional del gobierno es la expansión de la señal del pequeño canal de televisión Vive TV, canal que saliera al aire el 11 de noviembre del 2003 como espacio audiovisual "con características formales y de contenido dirigidos sustancialmente a las comunidades, como fuente y escenario de una realidad que ha sido negada o prácticamente excluida por las televisoras privadas", según afirmara su primera presidenta y fundadora Blanca Eekhout; y la puesta en funcionamiento de Telesur. Además del proyecto de dotar al país de un satélite propio en los próximos años.

\section{Para cerrar}

Para los que creemos en la Libertad y en la Democracia-con mayúsculas ambas- estos tiempos que corren en el país no son los más proclives para la realización de esos ideales, ni siquiera en el mediano plazo. Es evidente que rondan en la atmósfera otros conceptos acerca de esas palabras y que se ponen de manifiesto en todo el conjunto de publicaciones que promueve el gobierno y en los actos majestuosos que se proyectan desde él. Vivimos un "desconcierto ideológico" en el sentido de que:

Nuestras palabras clave están enfermas: están degradadas, se han vuelto obsesivas, se repiten a tontas y a locas, y con ellas se pretende conocerlo y explicarlo todo. Han perdido virtud operativa y han adquirido virtud mágica de exaltación o de exorcismo (...). Nuestras palabras clave se han agujereado, se han vuelto ciegas y cegadoras. Creíamos que iluminaban la naturaleza de la realidad social y política; descubrimos que nos la camuflaban (...). Pues bien, las palabras no son lo real. Traducen lo real por mediación de las ideas. El problema de las palabras remite, pues, al de las relaciones entre las ideas y lo real. ${ }^{33}$

33 MORIN, Edgar. Para salir del siglo XX. Madrid: Kairós, 1981, pp. 64-65. 
En tal sentido, los ideales de Libertad y Democracia que reivindico son el del reconocimiento y expresión de la diversidad cultural del país, el de la diversidad y respeto a la pluralidad ideológica y política, el de la necesaria disidencia con fundamento en la razón, el de la garantía de información plural... De lo contrario entramos en una realidad de país que se va pareciendo cada vez más a todo lo que hemos venido negando como realidad de país y de sociedad.

El poeta Rafael Cadenas nos ofrecía en el año 2001 un extraordinario texto Sobre la barbarie en el que se explayaba sobre el sentido y los sentidos que encierra ese término convertido, en muchas partes del planeta tierra, tanto antes como ahora, en una realidad. No se trata, de nuestra parte, de cerrar con sentido apocalíptico, pero como decía Umberto Eco en alguna parte: "Estos son hechos, nos gusten o no, y los hechos son tales precisamente porque son independientes de nuestras preferencias”. Así, escribía Cadenas:

Después de este recorrido es natural preguntarse hoy, en el umbral del siglo XXI, qué se puede hacer ante la barbarie, y no creo que haya una respuesta definitiva. Hay quienes piensan que es posible un cambio de mentalidad que no se quede en la superficie, en el nivel de las ideas.
Lo que hemos vivido en esta época basta para desengañarlos. Ya sabemos que el hombre nuevo de que se ufanaba el país socialista modelo no era tal, seguía siendo el hombre de siempre con el agravante de estar privado de libertad, aterrado por el big brother, aplastado por el leviatán totalitario, luego el Partido, y su líder, el nuevo dios, quien había decidido que representaba al pueblo, la revolución, la historia, el futuro, la verdad, el paraíso y era el único que en realidad hablaba; a los demás sólo les correspondía oír porque habían perdido el idioma. Semejantes encarnaciones son funestas. El hombre nuevo era, pues, un ser mutilado que ni podía sacar del pecho su voz.

Es evidente que todas las revoluciones han sido un fracaso, además con un costo incalculable de sangre, pero todavía hay personas, casi siempre generosas, que creen en la de nuestro tiempo. Tal vez piensan que la próxima será distinta, que la libertad será preservada, que se evitarán los errores cometidos por las anteriores, y por fin las mañanas cantarán, pero de hecho lo que hacen es perder el presente, el otro nombre de la vida, sacrificándolo en nombre de una fantasmagórica tierra. Podrían optar por la evolución, pero ella no es espectacular, no posee rebrillos alucinantes, no se presta para el lucimiento del yo, no brinda muchas ocasiones para los discursos excesivos, no alienta esa hybris que los dioses castigan. Es modesta, es prudente, es cívica. ${ }^{34}$

34 CADENAS, Rafael. "Sobre la barbarie", en VARIOS AUTORES. Venezuela siglo XX. Visiones y testimonios. Libro 2. Caracas: Fundación Polar, 2001, pp. 575-576. 


\section{Bibliografía:}

AGUIRRE, Jesús María. "La credibilidad en juego". SIC. Año LXVII, núm. 666. Caracas: Centro Gumilla, julio del 2004.

AUGÉ, Marc. Los "no lugares". Espacios del anonimato. Una antropología de la sobremodernidad. Madrid: Gedisa, 1996.

BOLADERAS, Cucurella. "La opinión pública en Habermas". Anàlisi 26. Barcelona: Departamento de Periodismo y Ciencias de la Comunicación de la Universidad Autónoma de Barcelona, 2001.

BORRAT, Héctor. El periódico, actor político. Madrid: Gustavo Gili, 1989.

CABRUJAS, José Ignacio. "El Estado del disimulo", en VARIOS AUTORES. Heterodoxia y Estado. Caracas: Comisión Presidencial para la Reforma del Estado, 1987.

CADENAS, Rafael. "Sobre la barbarie", en VARIOS AUTORES. Venezuela siglo XX. Visiones y testimonios. Libro 2. Caracas: Fundación Polar, 2001.

CAÑIZÁLEZ, Andrés. "El poder real". SIC. Años LXVII, núm. 666. Caracas. Centro Gumilla, julio del 2004.

CORREA, Carlos y Yubi CISNEROS Yubi. "La libertad de expresión en la reforma del Código Penal". Comunicación 130. Caracas: Centro Gumilla, segundo trimestre del 2005.
GUANIPA, Moraima. "Hacer cultura y dar cultura: Inventario de una heterogeneidad", en varios autores. Venezuela siglo XX. Visiones $y$ testimonios. Libro 2. Caracas: Fundación Polar, 2001.

HABERMAS, J. Historia y crítica de la opinión pública. Madrid: Gustavo Gili, 1981.

- Facticidad y validez. Madrid: Trotta, 1998.

LINZ, Juan. La quiebra de las democracias. México: Patria, 1990.

LUHMANN, Niklas. La realidad de los medios. Barcelona: Iberoamericana/Anthropos, 2000.

MARÍAS, Julián. Ser español. Ideas y creencias en el mundo bispánico. Barcelona: Planeta, 2001.

MARTÍN-BARBERO, Jesús. "Reconfiguraciones comunicativas de lo público". Anàlisi 26. Barcelona: Departamento de Periodismo y Ciencias de la Comunicación de la Universidad Autónoma de Barcelona, 2001.

- -Colombia: Ausencia de relato y desubicaciones de lo nacional", en VARIOS AUTORES. Imaginarios de nación. Bogotá: Ministerio de la Cultura de Colombia, 2001.

MARTÍNEZ, Ibsen. "La televisión de señal abierta y sus consensos". El Nacional. Caracas, 13 de setiembre del 2004.

MIRES, Fernando. 'Los diez peligros de la democracia en América Latina", 
2005 [en línea]. Nueva Sociedad. Sección de Intervenciones. $<$ http://www.nuevasoc.org.ve>.

MOLEIRO, Alonso. "Traigan de vuelta al periodismo". Comunicación 127. Caracas: Centro Gumilla, 2004.

MORIN, Edgar. Para salir del siglo XX. Madrid: Kairós, 1981.

MOUCHAN, Jean. Politica y medios. Los poderes bajo influencia. Barcelona: Gedisa, 1999.

ORTIZ, Renato. "Brasil: sociedad, cultura y nación”, en VARIOS AUTORES. Imaginarios de nación. Bogotá: Ministerio de la Cultura de Colombia, 2001.

PINO ITURRIETA, Elías. La cultura de Venezuela. Historia minima. Caracas: Fundación de los Trabajadores de Lagovén, 1996.

- - et al. Historia mínima de Venezuela. Caracas: Fundación de los Trabajadores de Lagovén, 1996.

SARLO, Beatriz. "Ser argentino: ya nada será igual", en VARIOS AUTORES. Imaginarios de nación. Bogotá: Ministerio de la Cultura de Colombia, 2001.
SCHARFENBERG, Ewald. "Periodismo venezolano. De un esplendor supuesto al raquitismo". Comunicación 131. Caracas: Centro Gumilla, tercer trimestre del 2005.

SIC. "La toma total del poder ¿es el mejor camino?" SIC 675. Año LXVIII, núm. 675. Caracas: Centro Gumilla, junio del 2005.

VÁZQUEZ, Rodolfo. ¿Qué es el Estado de derecho? Un punto de vista liberal. México, D.F.: Instituto Tecnológico Autónomo de México, 2003.

VELÁSQUEZ, Ramón J. Balance del siglo XX. Caracas: Fundación Francisco Herrera Luque/Grijalbo, 1996.

ZELLER, Carlos. "Los medios y la formación de la voz en una sociedad democrática", en la revista Anàlisi 26. Barcelona: Departamento de Periodismo y Ciencias de la Comunicación de la Universidad Autónoma de Barcelona, 2001. 